\title{
Vietnamese English Teachers' Perceptions on Incorporating World Englishes Into Their Teaching
}

\author{
Tran Thi Hao \\ Vinh University, Vietnam \\ Paul Moore \\ The University of Queensland, Australia
}

\begin{abstract}
Understanding English varieties other than native-speaker norms has been regarded as necessary for effective communication in contexts where English is used as a lingua franca. In Vietnam, however, English language teaching remains focused on Standard English, which is somewhat out of step with the role of English in communication in the region. This exploratory study aims to uncover Vietnamese English teachers' perceptions of World Englishes (WE) in their English teaching. An online questionnaire, five individual follow-up interviews, and one focus group interview were conducted. A broad range of perceptions of Vietnamese English teachers at the university / college level towards English varieties was found. Introducing these was noted as having various benefits and challenges for teaching and learning. Suggestions for incorporating WE into teacher training, teaching, and materials development were deduced from the study, as were participants' imagined plans and implications of these plans for English teaching in Vietnam.
\end{abstract}

Understanding varieties of English, or World Englishes (WE), is considered a crucial task in language teaching and learning to prepare English users for effective and intelligible communication. In light of WE, English is argued to have become a denationalized language which is no longer tied to native speakers in terms of linguistic usage (Jenkins, 2006; Seidlhofer, 2004; Widdowson, 1994). Introducing these Englishes to language learners parallels the ongoing increase in the number of non-native English speakers and communication among non-native speaker communities (Crystal, 1997; House, 2003; Kachru, 2005). The relevance of native-speaker norms in communicative activities outside native-English countries has also been brought into question (Brutt-Griffler, 2002; Canagarajah, 2006; Jenkins, 2000, 2006; McKay, 2002; Ton \& Pham, 2010). Despite this increasing importance of WE in English teaching, very few studies have been conducted in Vietnam to explore the kinds of English used or the perceptions of English teachers towards WE. The study reported here thus aims to shed light on the perceptions of English teachers at the university / college level in Vietnam towards incorporating WE in their English teaching contexts.

Language Education in Asia, 2015, 6(2), 107-121. http://dx.doi.org/10.5746/LEiA/15/V6/I2/A3/Tran_Moore 


\section{Literature Review}

This section presents studies conducted in the field from the broader context of Asia, to the ASEAN community, and Vietnamese teaching contexts.

In some Asian contexts, such as India and Pakistan, new Englishes are widely recognised (Kandiah, 1998), while in others, such as Japan, where English is mainly used as a foreign language, the awareness and acceptance of WE are lower (Samida \& Takahashi, 2011). Suzuki (2011) investigated three Japanese student teachers' understanding of the diversity in English and their perspectives on introducing WE into English language teaching in Japan. Individual interviews along with student writing were explored in the study. Participants in the study displayed different levels of knowledge about varieties of English, which Suzuki attributed to their prior experiences of social and educational interaction with other second language speakers of English. Nonetheless, only American and British English were regarded as appropriate for English language teaching. The study recommended developing teachers' perceptions of other varieties of English in teacher preparation programs as well as developing skills in teaching English as an international language.

Within the ASEAN community, English plays the role of de facto lingua franca (Krasnick, 1995) and has been a working language of ASEAN as an institution since 2007 (Kirkpatrick, 2008). Among several studies in ASEAN contexts (Brown \& Deterding, 2005; Lowenberg, 1991), Moore and Bounchan (2010) examined Cambodian English by employing questionnaires and focus group interviews. The study investigated the perceptions of teachers, administrators, and students as to the status of Cambodian English, and their preferences for different kinds of English. It revealed that English in Cambodia is perceived as "a second language or international language rather than a foreign language or lingua franca" (Moore \& Bounchan, 2010, p. 121), along with the recognition of Cambodian English. Furthermore, although one particular Standard English variety was preferred in classroom teaching, others were also drawn on as the context dictated. Moore and Bounchan concluded that a balance was needed between teaching Standard English and newer varieties.

In line with the recognition of WE among many countries within the ASEAN region, it has been argued that Vietnam should develop an understanding of WE to develop and promote "mutual intelligibility" (Kirkpatrick, 2007, p. 193). Nonetheless, the current trend in English language teaching in Vietnam is to privilege British and American standard English. Of the few studies that exist discussing WE or issues of different Englishes in the context of Vietnam, Ton and Pham's (2010) is directly related to the present study. With the participation of 250 students and 80 university teachers from two universities in Vietnam, the study investigated attitudes towards the preferred kinds of English via a mixed-method approach involving questionnaires and interviews. The study found that although students used English more often with nonnative speakers, they still preferred studying British and American English. Ton and Pham also suggested that students should explore more English varieties outside the classroom for more effective communication with non-native speakers.

To further explore the perceptions of Vietnamese English teachers towards WE, a broad perspective on teachers' participation is expected to provide a range of perceptions along with a deep understanding of their attitudes. The current study thus aims to answer the following research questions: 
1. What are Vietnamese English teachers' beliefs towards WE and issues concerning varieties of English?

2. What are their beliefs regarding introducing English varieties in their English teaching?

3. How might the teachers introduce varieties of English into their English teaching? What are the perceived advantages and challenges?

\section{Methods}

A mixed-methods approach (involving both quantitative and qualitative data) was employed to answer the research questions; such an approach is argued to produce a more comprehensive understanding of the research situation than collecting only one type of data (Tashakkori \& Teddlie, 1998). It has three main characteristics, including timing, weighting, and mixing (Creswell \& Plano Clark, 2007). In the current study, mixed methods research is utilized as a sequence (timing) with a stronger focus on qualitative data (weighting).

Vietnamese English teachers at the university / college level in Vietnam were selected to take part in the first stage of the research, an online questionnaire (see Appendix A), for salient reasons. First, among Vietnam teaching contexts, university teachers have more autonomy than primary or secondary teachers in the choice of teaching materials and teaching content. Their students may have stronger language proficiency and more experience of other kinds of English through overseas studies or workplace requirements. The choice of participants thus relates to the teachers' consideration of introducing WE in their teaching contexts. Therefore, only the responses of the respondents at university / college level (76) were used for the study from a total of recruited respondents (81) from a snowball online questionnaire. Further information on participants for each stage of the research is outlined below and in the following section.

Five of the participants, Vietnamese English teachers pursuing a master's degree in Applied Linguistics at an Australian university, took part in the interview stage, including individual semi-structured interviews (see Appendix B) and a focus group interview (see Appendix C), after they had answered the online questionnaire. These teachers had encountered courses relating to WE in their master's programs. Potential changes in their perceptions towards WE, compared with what they had understood before studying in an overseas university, were considered an important aspect of the investigation. Their views on the importance of different kinds of English in teaching and learning and in communication through daily contact with the diverse varieties of English in Australia were also of interest. Their imagined plans or actions relating to introducing these Englishes in their teaching when they returned to their home country were also expected to contribute to the understanding of its further implications for English teaching and learning in Vietnam.

The data collection process took place over a period of six weeks. In analyzing the data, the first author classified the participants into subgroups according to their teaching major and their previous experiences of WE. Quantitative data were analysed for trends and variance by providing frequencies and percentages. Qualitative data were the major focus of data analysis. Individual and focus group interview data were firstly transcribed and then analysed and interpreted through four stages: reading, coding, sorting, and interpreting. The online questionnaires and interviews (individual and focus group interviews) were conducted in English. Excerpts from the interview data in the following section are presented in participants' own words, including any non-standard forms and expressions. 


\section{Findings}

Detailed findings of the three main sections including online questionnaire, individual interviews, and the focus group interview are presented in this section.

\section{Online Questionnaires}

After providing detailed information on the participants, this section provides findings from the online questionnaire.

\section{Table 1}

General Description of Participants in Online Questionnaires

\begin{tabular}{|c|c|c|c|c|c|c|c|c|}
\hline $\begin{array}{l}\text { Number of } \\
\text { participants }\end{array}$ & \multicolumn{2}{|c|}{ Gender } & \multicolumn{5}{|c|}{ Age range } & $\begin{array}{l}\text { Total } \\
\text { number of } \\
\text { universities } \\
\text { / colleges }\end{array}$ \\
\hline \multirow{2}{*}{$N=76$} & Female & Male & $\begin{array}{c}\text { Under } \\
25\end{array}$ & $26-30$ & $31-35$ & $36-40$ & $\begin{array}{c}\text { Above } \\
40\end{array}$ & \multirow{2}{*}{26} \\
\hline & $\begin{array}{c}56 \\
(73.7 \%)\end{array}$ & $\begin{array}{c}20 \\
(26.3 \%)\end{array}$ & $\begin{array}{c}2 \\
(2.6 \%)\end{array}$ & $\begin{array}{c}34 \\
(44.7 \%)\end{array}$ & $\begin{array}{c}24 \\
(31.6 \%)\end{array}$ & $\begin{array}{c}5 \\
(6.5 \%)\end{array}$ & $\begin{array}{c}11 \\
(14.5 \%)\end{array}$ & \\
\hline
\end{tabular}

Overall, seventy-six participants were Vietnamese English teachers at 26 universities / colleges in Vietnam (see Table 1). Regarding the question "Did you encounter the term WE before?" 57 (75\%) answered "Yes" whereas 19 (25\%) answered "No." This, to some extent, shows unequal understanding or contact with this term among teachers in Vietnam. As for the question exploring the variety of English currently widely used in English teaching in Vietnam, 89\% responded "American or British English" and 11\% "both American and British English." "American and / or British English" was also the most common answer (77\%) to a question addressing the variety of English currently used most in English teaching materials in Vietnam.

Seventy-one percent of the respondents chose the answers "strong" or "very strong" when asked about the influences of native varieties on English teaching in Vietnam. This is consistent with the results of an open question asking respondents to nominate the varieties of English which have the strongest influences on English teaching in Vietnam. The most common answer to this question was "British and / or American English" (86\%).

The respondents posited that students communicate more with non-native-speakers (75\%) than native speakers. Interestingly, a majority of the respondents regarded "Vietnamese English" as an acceptable term (58\%) with three main features noted as pronunciation, grammar / syntax, and culture. Accent was chosen to be the most common criterion to distinguish different kinds of English at $71 \%$. Other criteria such as vocabulary, culture, and grammar constituted $10 \%$, $9 \%$, and $1 \%$ respectively. The option "Others" received $9 \%$ of the responses though no specific criteria were denoted as part of this open-ended response.

Due to the length limitations for this article, only prominent issues from the questionnaire are presented in this section. Further data related to the online questionnaire are presented in the Discussion section.

\section{Individual Interviews}

Two male (Linh and Manh) and three female (Suong, Thanh, and Tu) participants (pseudonyms used), ranging in age from 26 to 31, from various cities in Vietnam, participated in the individual interviews. Different experiences with the term WE were reported - through TESOL 
workshops or colleagues' presentations (Suong and Manh) or MA courses (Thanh). Although Linh had encountered this term before, he did not express a clear understanding of it. He stated: "I heard this term two years ago but I did not know anything about this, also, I did not try to explore what it is."

All of the interviewees agreed that introducing WE was important to English teaching. Linh emphasized "it is really important to help the learners understand and as teachers we should introduce students with varieties of English." In support, Suong stated "the job of teaching is to prepare students for real-life later to avoid the shock later when they are exposing with other varieties of English". However, the interviewees still mentioned their doubts about how to introduce them effectively, as well as the challenges they expected to encounter.

Regarding the interviewees' experiences of incorporating different English varieties into their teaching, most of them stated that they had not employed anything other than British and American English. Difficulties in diverse teaching contexts were challenges for their introduction: teaching and learning materials, issues related to time and effort, the selection of the kind of English to be introduced, and students' resistant attitudes. "Number one ..., lack of materials, number two, that would be very time and effort consuming, and also another major issue is important is the resistance of part of students ..." (Manh). Interestingly, all of the participants reported their plan to introduce different Englishes. Thanh said that, "I think after I finish my MA, the way of my teaching has to change."

Regarding the introduction of WE in their classes, interviewees suggested different ideas, including activities they could do, as well as what institutions could do to support them. Conducting student needs analyses, raising students' and teachers' awareness, exploring attitudes, preparing for teachers and students' first encounter with other varieties of English, and investment in teacher education were all noted. Suong observed:

need analysis is very important to do here because if we, students and teachers both aware of the kinds of English they will use in future, their purposes of learning English or the kinds of English they will encounter later so the attitude may change.

Tu suggested the employment of technology and media as sources for introducing different Englishes. Manh noted that "the teachers should introduce, inspire students with English varieties because students are still more interested in studying native varieties." Careful preparation for the students' first encounter with different kinds of English was also considered an important task to reduce the possible initial shock and ease the conservative attitudes of the students towards these varieties.

\section{Focus Group Interview}

In the focus group interview, participants discussed the prominent statements extracted from the online questionnaire and individual interviews along with their imagined actions relating to introducing WE after graduation.

When asked their opinions towards the statement reflecting one of the benefits of introducing WE, "introducing English varieties, especially non-native varieties, helps students to be confident with their own English and proud of their own English variety," the participants presented different points of view. Manh and Thanh agreed with this idea and posited that accent is not very important. Thanh claimed that: "I focus on more communication, fluency and a bit on accuracy; the accent needs to be accepted to identify identity". Despite agreeing with this, Suong 
suggested that students' confidence in their own abilities "should be taken with caution. It may mislead students into believing that they do not need improvement." However, all participants expressed positive attitudes towards other kinds of English, both native and non-native.

The second statement in the focus group interview discussed the issue of native-like competence as the main goal of teaching, which reflects the contention that introducing different Englishes into teaching is unnecessary. All interviewees agreed with Manh's opinion that "native-like is most of the time not the target of learning English but the effectiveness on communication." Tu suggested the level of students' proficiency should be taken into account when introducing other varieties of English to reduce students' confusion.

The third issue discussed was the exam-oriented status of teaching and learning English in Vietnam, which may be implicated in the strong focus on teaching British and American English. All interviewees emphasized the necessity of an analysis of students' needs to identify the students' purposes for learning English to choose suitable teaching contents and methods. They also stressed the need for exposure to different Englishes in real-life communication. They claimed that introducing WE in teaching would not aim to change the learners' goals or targets (e.g., away from exam-oriented purposes); rather the aim would be to raise awareness of the kinds of English students may be likely to encounter. Manh further noted the reality that few learners in foreign language settings can be expected to reach the goal of native-speaker-like competence, adding that "[n]o matter how hard we try, we cannot reach the target (Standard English)."

With regard to introducing WE, Linh suggested that since he was teaching both major and nonmajor students, they should be introduced to it step-by-step through consultation with teaching staff. In other words, consensus among teachers is necessary to decide appropriate ways to introduce these Englishes. Specifically, Manh noted that he would employ a task-based language teaching (TBLT) approach to "help the students figure out the way to understand and explore more ideas of English varieties through Internet," whereas Thanh suggested their introduction through courses in listening skills or intercultural communication. Organizing related workshops or publishing research about WE to widen teachers' awareness and acknowledgement of it were also mentioned.

When discussing which kinds of English to teach, Linh stated that he preferred teaching those from ASEAN countries but suggested that this should be a decision made by teaching staff in specific contexts. Suong added that "how is more important than what" and recommended introducing them in a less formal (non-assessed) way, stating "do not take it as a big deal as the students are assessed." She also suggested that the teachers should consider the likelihood of encounters with those Englishes to choose suitable ones to introduce.

\section{Discussion}

Vietnamese English teachers' perceptions of World Englishes are discussed under the analysis of three research questions with the data drawn from both questionnaire and interviews.

\section{Research Question 1: What Are Vietnamese English Teachers' Beliefs Towards WE and Issues Concerning Varieties of English?}

Participants in the study provided diverse opinions towards WE. The difference was firstly shown through their reported encounters with the term WE. Although a number of features have been identified in the literature to distinguish different Englishes, such as phonological features, lexical features, syntax, or cultural conventions (Brown \& Deterding, 2005; Deterding \& Kirkpatrick, 2006; Kirkpatrick, 2007; Lowenberg, 1991; McArthur, 2002), accent was regarded by these Vietnamese English teachers as the most important distinguishing feature. 
In terms of the teachers' awareness of English varieties, American and British English were all acknowledged by the participants. They also acknowledged other non-native kinds of English, such as those in the ASEAN region. Notably, Vietnamese English was more widely reported by the participants as an acceptable term along with its features in terms of pronunciation, grammar, and culture, which were noted in reference to differences between Vietnamese and English. However, whereas tenses were pointed out as grammatical features of Indonesian English (Kirkpatrick, 2007), word order ("house big," not "big house") and the use of articles or plural features ("two book," not "two books") were noted by participants as features of Vietnamese English. Vietnamese cultural norms involving direct questions of a personal nature (e.g., related to age, marital status, or financial status) were included as Vietnamese English features, which is to some extent similar to the results of Srihar (1991) regarding request strategies of Indian English transferred from local languages (as cited in Kirkpatrick, 2007).

Native and non-native Englishes were perceived by participants as having different roles and positions in English teaching in Vietnam. Native Englishes were commonly believed by the participants to be widely used and to exert a strong influence on English teaching and assessment, supporting the findings of Ton and Pham (2010). Native Englishes were explained as the kinds currently used in course books or English teaching materials used in English courses in Vietnam. These materials include English-language media such as films or game shows which extensively influence daily life in Vietnam. Importantly, international tests, namely IELTS, TOEFL, and TOEIC, were regarded by the participants as an important goal for Vietnamese students - all these tests currently privilege native varieties of English.

The importance of non-native kinds of English was also noted by many teachers in the study. Supporting Kirkpatrick's (2002) findings, the current study showed that Vietnamese students are more likely to communicate in English with non-native speakers than native speakers. Similarly, non-native varieties were claimed by the participants to contribute to successful communication, which focuses more on fluency than accuracy.

\section{Research Question 2: What Are Vietnamese English Teachers' Beliefs of Introducing English Varieties in Their English Teaching?}

The study's participants stated that introducing WE into English teaching in Vietnam was an important and necessary task and was regarded as providing definite advantages. First, it was argued that the introduction of WE would prepare students for real-life encounters with different kinds of English, a beneficial factor for successful communication, and would help to change or improve students' confidence and awareness of English varieties, especially their own. These findings support those reported by Kirkpatrick (2007) and Honna and Takeshita (2000). In addition, introducing WE, especially non-native types, was seen by participants as a way of changing Vietnamese expectations of, and reliance on, standard native-English models.

However, introducing other Englishes was also perceived by the participants as a challenge for English teachers. First, lack of proper teaching materials is a major problem, as most current teaching materials draw on American or British standard English. Second, as with other innovations, requirements in time and effort were reported as one issue that needed to be taken into consideration. Linh, for example, stated that there was "no extra time for introducing these varieties." Teachers' awareness and knowledge of WE was also regarded as a constraint. Participants stated that they did not have enough information or contact with different kinds of English. Importantly, the teachers also stated that their students might show reluctance, resistance, or confusion on encountering non-standard English in the classroom. For example, Thanh stated that "students may get bored with those non-native English varieties" because "they just want to study native speaker voices only." 


\section{Research Question 3: How Might The Teachers Introduce Varieties of English Into Their English Teaching? What Are The Perceived Advantages and Challenges?}

With regard to introducing varieties of English, different teaching contexts revealed diverse perceived advantages and challenges. Therefore, to develop a suitable approach to their introduction, teachers must carefully consider each teaching context to employ appropriate actions in teaching or "clear and consistent learning models" (Swan, 2012, p. 384). The participants in this study suggested that different kinds of English must be introduced carefully, as learners may demonstrate confusion and resistance, or at an appropriate stage, as noted by Sewell (2013). It was also recommended that using workshops or informal presentations based on teachers' personal experiences could help raise students' awareness of this topic and its importance. The participants regarded this as an important step before teachers commence introducing WE.

The participants also posited that once the students were aware of the importance of understanding different English varieties, introducing the varieties must be conducted motivationally, such as through warm-up activities or through engaging media such as YouTube. Introducing different kinds of English through English clubs with students' performance was also suggested as a means of encouraging students to explore WE.

In universities with support for teaching WE, the participants recommended these Englishes be introduced through TBLT. This approach may afford students the autonomy to select which varieties of English they may want to explore. Tasks related to real-life situations might also intrigue and stimulate students with the exploration and understanding of different kinds of English, as noted by Matsuda (2003). In universities or colleges with no courses relating to WE, the participants suggested that these tasks could be attached to other courses such as intercultural communication or listening subjects. In these certain circumstances, teachers could also use podcasts, YouTube videos, or intercultural movies (cf. Kachru \& Nelson, 2006) to introduce different Englishes.

Regarding teachers' knowledge and awareness, the participants reported that changing teachers' conservative attitudes towards other Englishes, including non-native varieties, was an important task. They also recommended holding workshops, teachers' meetings, and discussions about WE. In contrast to Matsuda's (2003) suggestions of bringing in speakers of different varieties into classrooms or changing the recruitment process to include more non-native English teachers, the participants in this study focused more on investment in overseas teacher training such as that provided by the Vietnamese Ministry of Education and Training. Through their experiences overseas with issues related to other kinds of English, participants noted that they believed that overseas training provides English teachers with real-life experiences to improve their awareness of teaching issues in international contexts.

\section{Conclusion}

The study reported here explored Vietnamese English teachers' perceptions of World Englishes as well as their beliefs regarding their introduction. Perceptions, suggestions, and imagined actions of the study's participants provide insights into the current experience of teachers who work in contexts where the variety of English taught is not necessarily representative of the varieties students may be exposed to living and working in the ASEAN region. The research also adds to the limited amount of literature on WE in Vietnam, and provides evidence of the potential influence of WE in English language education in a region which is becoming increasingly interconnected and where competence in different kinds of English is destined to become necessary for successful intercultural communication. 
The research has several implications for English teaching and language policy in Vietnam. First, there is a need to provide teacher training to improve teachers' knowledge and awareness. English teachers should also have opportunities to involve themselves in real-life English communication via funded short-term or long-term overseas courses. Further discussions or workshops should also be held to reach a consensus among teachers regarding the best methods for including WE in specific contexts. A degree of autonomy, for both teachers and learners, is also required so the varieties of English drawn on in the curriculum are most relevant to their current and future needs.

While this study has provided the insights outlined above, the findings are limited in terms of generalizability, as well as the participants chosen. First, the short turnaround time and limited numbers of participants in the study, with a focus on university and college teachers only, restricts its generalizability. Further, though unique traits of the interview participants (studying in Australia) provided an important perspective on the current and imagined future roles of WE in Vietnam, the voices of other teachers are also needed to provide a more in-depth understanding of the findings from the online questionnaire.

Further research thus needs to be conducted over a longer period to grasp the breadth of views expressed. Moreover, future studies should investigate the perspective of teachers who are teaching English in Vietnam and are thus directly influenced by their particular social and educational contexts. In addition, students' perspectives towards English varieties need further exploration rather than solely drawing on their teachers' interpretations. Finally, more work is needed into the analysis of Vietnamese English features to provide researchers, teachers, and learners with a clear understanding of what makes this variety of English unique.

\section{Author Note}

Tran Thi Hao, Foreign Languages Department, Vinh University, Vietnam; Paul Moore, School of Languages and Cultures, University of Queensland, Australia.

Tran Thi Hao obtained her Master of Applied Linguistics from the University of Queensland and is currently a PhD candidate at Griffith University, Australia. Prior to this, she was an English lecturer at Vinh University, Vietnam. Her major research interests include teacher professional development, World Englishes, and language policy.

Paul Moore is a lecturer in Applied Linguistics at the University of Queensland. His research interests include second language acquisition, task-based language teaching from social / cognitive perspectives, intercultural communication, and language assessment. He convenes the MA coursework dissertation and teaches courses in research methods, language and technology, and intercultural communication.

Our sincere thanks go to colleagues in Vietnam and Australia for their involvement in the study. This paper is based on the first author's master's thesis.

Correspondence concerning this article should be addressed to Tran Thi Hao. E-mail: haotran203@gmail.com 


\section{References}

Brown, A., \& Deterding, D. (2005). A checklist of Singapore English pronunciation features. In D. Deterding, A. Brown, \& E. L. Low (Eds.), English in Singapore: Phonetic research on a corpus (pp. 7-14). Singapore: McGraw Hill.

Brutt-Griffler, J. (2002). World English. A study of its development. Clevedon, England: Multilingual Matters.

Canagarajah, A. S. (2006). Negotiating the local in English as a lingua franca. Annual Review of Applied Linguistics, 26, 197-218. http://dx.doi.org/10.1017/S0267190506000109

Creswell, J. W., \& Plano Clark, V. L. (2007). Designing and conducting mixed methods research. Thousand Oaks, CA: Sage.

Crystal, D. (1997). English as a global language. Cambridge, England: Cambridge University Press.

Deterding, D., \& Kirkpatrick, A. (2006). Intelligibility and an emerging ASEAN English lingua franca. World Eng/ishes, 25(3), 391-410. http://dx.doi.org/10.1111/j.1467971X.2006.00478.x

Honna, N., \& Takeshita, Y. (2000). On Japan's propensity for native speaker English: A change in sight. Asian Englishes, 1(1), 117-137. http://dx.doi.org/10.1080/13488678.1998.10800997

House, J. (2003). English as a lingua franca: A threat to multilingualism? Journal of Sociolinguistics, 74), 556-578. http://dx.doi.org/10.1111/j.1467-9841.2003.00242.x

Kandiah, T. (1998). Why new Englishes? In J. Foley, T. Kandiah, B. Zhiming, A. Gupta, L. Alsagoff, C. L. Ho, L. Wee, I. S. Talib, \& W. Bokhorst-Heng (Eds.) English in new cultural contexts: Reflections from Singapore (pp. 1-40). Singapore: Singapore Institute of Management / Oxford University Press.

Jenkins, J. (2000). The phonology of English as an international language. Oxford, England: Oxford University Press.

Jenkins, J. (2006). Current perspectives on teaching World Englishes and English as a lingua franca. TESOL Quarterly, 4O1), 157-181. http://dx.doi.org/10.2307/40264515

Kachru, B. (2005). Asian Englishes beyond the canon. Hong Kong: Hong Kong University Press.

Kachru, Y., \& Nelson, C. (2006). Asian Englishes Today: World Englishes in Asian contexts. Hong Kong: Hong Kong University Press.

Kirkpatrick, A. (2002). ASEAN and Asian cultures and models: Implications for the ELT curriculum and teacher selection. In A. Kirkpatrick (Ed.), Englishes in Asia: Communication, identity, power and education (pp. 213-224). Melbourne, Australia: Language Australia.

Kirkpatrick, A. (2007). World Englishes: Implications for international communication and English language teaching. New York, NY: Cambridge University Press.

Kirkpatrick, A. (2008). English as the official working language of the Association of Southeast Asian Nations (ASEAN): Features and strategies. English Today, 24(2), 27-34. http://dx.doi.org/10.1017/S0266078408000175

Krasnick, H. (1995). The role of linguaculture and intercultural communication in ASEAN in the year 2020: Prospects and predictions. In M. L. Tickoo (Ed.), Language and culture in multilingual societies (pp. 81-93). Singapore: SEAMEO Regional Language Centre.

Lowenberg, P. (1991). Variation in Malaysian English: The pragmatics of language in contact. In J. Cheshire (Ed.), English around the world. Sociolinguistic perspectives (pp. 364-375). Cambridge, England: Cambridge University Press.

Matsuda, A. (2003). Incorporating World Englishes in teaching English as an international language. TESOL Quarterly, 37(4). http://dx.doi.org/10.2307/3588220

McArthur, T. (2002). The Oxford guide to World Englishes. Oxford: Oxford University Press.

McKay, S. L. (2002). Teaching English as an international language: Rethinking goals and approaches. Oxford, England: Oxford University Press. 
Moore, S. H., \& Bounchan, S. (2010). English in Cambodia: Changes and challenges. World Englishes, 29(1), 114-126. http://dx.doi.org/10.1111/j.1467-971X.2009.01628.x

Samida, D. K., \& Takahashi, J. (2011). World Englishes: What is an international language for the world? Hokkaido Bunkyo University Research Papers, 12, 49-59. Retrieved from http://libro.do-bunkyodai.ac.jp/research/pdf/tretises12/05-samida.pdf

Seidlhofer, B. (2004). Research perspectives in teaching English as a lingua franca. Annual Review of Applied Linguistics, 24, 209-239. http://dx.doi.org/10.1017/S0267190504000145

Sewell, A. (2013). English as a lingua franca: Ontology and ideology. ELT Journal, 671), 3-10. http://dx.doi.org/10.1093/elt/ccs061

Suzuki, A. (2011). Introducing diversity of English into ELT: Student teachers' responses. ELT Journal, 65(2), 146-153. http://dx.doi.org/10.1093/elt/ccq024

Swan, M. (2012). ELF and EFL: Are they really different? Journal of English as a Lingua Franca, 1(2), 379-389. http://dx.doi.org/10.1515/jelf-2012-0025

Tashakkori, A., \& Teddlie, C. (1998). Mixed methodology: Combining qualitative and quantitative approaches. Thousand Oaks, CA: Sage.

Ton, N. N. H., \& Pham, H. H. (2010). Vietnamese teachers' and students' perceptions of Global English. Language Education in Asia, 1, 48-61. http://dx.doi.org/10.5746/LEiA/10/V1/A05/Ton_Pham

Widdowson, H. G. (1994). The ownership of English. TESOL Quarterly, 28(2), 337-389. http://dx.doi.org/10.2307/3587438 


\section{Appendix A \\ Online Questionnaire}

I. Personal Information: Please circle the appropriate answer to you

1. Are you male $(M)$ or female $(F)$ ?
A. $F$
B. $M$

2. How old are you?
Under 25
B. $26-30$
C. 31-35
D. $36-40$
E. above 40

4. Are you teaching at the university / college level?
A. Yes
B. No

5. In which University or College are you teaching in Vietnam?

6. What majors and courses are you teaching? (e.g.: non-major English students or majorEnglish students)

6a. Have you ever studied in or visited another country where you have had to communicate in English?

6b. Which country or countries? (Only answer this question if you say yes in Question 6a)

6c. Did you have any difficulties in understanding the English used by people in that country? (Only answer this question if you say Yes in Question 6a)

$6 \mathrm{~d}$. What difficulties did you have and what do you think the reasons for these difficulties were? (Only answer this question if you say Yes in Question 6c)

II. Perceptions of English varieties

7a. Have you heard the term 'World Englishes'?
A. Yes
B. No

7b. In your opinion, what is the meaning of this term? (Only answer this question if you say Yes in Question 7a)

8. Which variety of English do you think is currently most widely used in English teaching in Vietnam?
A. American English
B. British English
C. Australian English

D. New Zealand English

E. Other answer:

9. Which variety of English is currently used most in your teaching materials (course books or other materials)?

10. How strongly do you think native varieties of English (i.e. American, British, Canadian, New Zealand, Australian English) influences English teaching in Vietnam?
A. Very strongly
B. Strongly
C. Fairly
D. Weakly
E. Not at all 
11. Which variety of English do you think has the strongest influences in Vietnam?

12. When we say "varieties of English", what varieties of English are you aware of?

13. Which variety of English do you think should be best fostered for English teaching in Vietnam?

14. What is the most important factor distinguishing this variety from the others?
A. Accent
D. Culture
B. Grammar
E. Other answer:
C. Vocabulary

15. Which variety of English do you think best describes your own English?

16. Which variety of English do you think your students aim to study?

17. What do you think are the three main purposes of your students in studying English?

18. Which people do you think that most of your students might communicate in English with?
A. Native speakers
B. Non-native speakers
C. Other answer:

19. What varieties of English do you think your student might encounter in daily communication in English?

20. Do you think introducing different varieties of English into English teaching is important?
A. Yes
B. No
C. Unsure

21. What do you think are foreseeable benefits when introducing different varieties of Englishes into your teaching?

22. What challenges do you think teachers might encounter when introducing other varieties of English (besides the native varieties)?

23. What are the most three important criteria that you use to assess a student is good at English?
A.
B.
C.

24. Which variety of English do you use as a model in your English testing?

25. Do you think "Vietnamese English" is an acceptable term?
Yes
B. No
C. Unsure

26. What are some features of English used by Vietnamese speakers that you recognize or acknowledge? Please provide examples 


\section{Appendix B}

\section{Individual Semi-Structured Interview}

The following are semi-structured interview questions that are going to be asked after the questionnaire results are analysed.

1. Which semester are you studying at the University of Queensland? What university are you teaching at in Vietnam?

2. Have you studied or encountered the term "World Englishes" (WE)?

3. Did you know this term WE before you attend this Master Course? In your opinions, what does this term mean?

4. Which varieties of English were you aware of before you attend this Master Course?

5. Do you think that your case is the same with most of other Vietnamese teachers in Vietnam?

6. Do you think understanding WE or English varieties are important to English teaching in Vietnam / to daily communication? How?

7. Have you ever employed different English varieties into your English teaching? If yes, how was it? What are your students' attitudes towards those varieties you think? If no, why?

8. What are some obvious challenges that you think when introducing English varieties into English teaching in Vietnam?

9. Do you think you will employ WE or varieties of Englishes into your teaching context later on when you graduate? What are your future / imagined actions in terms of introducing English varieties into your teaching context when you come back your home country?

10. What are some suggestions that you would make to introduce English varieties in English teaching in your contexts? 


\section{Appendix C \\ Focus Group Interview}

1. It is presented that: "introducing English varieties, especially non-native varieties, helps students to be confident with their own English and proud of their own English variety" What do you think about this idea?

2. It is said that: the ultimate purpose of teaching and learning English is to achieve a native-like or as close to native-like level as possible. (We thus need to aim to Standard English for English teaching.) Introducing English varieties only make students confused and distracted with Standard English and their target.

3. The aims / target of teaching and learning English in Vietnam is examination-oriented, which is focused on TOEIC, TOEFL, IELTS (Standard English). Therefore, the teacher only needs to focus on teaching these varieties (British and American English). What do you think about this?

4. What are some suggested solutions of introducing English varieties? Which varieties should we teach and how to teach?

5. What are suggested plans to introduce English varieties into English teaching context in Vietnam? 